\title{
Towards a Process Model of Sustained Attention Tests
}

\author{
Iris Blotenberg *(D) and Lothar Schmidt-Atzert \\ Department of Psychology, Philipps-University of Marburg, Gutenbergstr. 18, 35032 Marburg, Germany; \\ schmidt-atzert@uni-marburg.de \\ * Correspondence: iris.blotenberg@staff.uni-marburg.de
}

Received: 6 December 2018; Accepted: 24 January 2019; Published: 28 January 2019

\begin{abstract}
Taking up new approaches and calls for experimental test validation, in the present study we propose and validate a process model of sustained attention tests. Four sub-components were postulated: the perception of an item, a simple mental operation to solve the item, a motor reaction, and the shift to the next item. In two studies, several cognitive tasks and modified versions of the $\mathrm{d} 2-\mathrm{R}$ test of sustained attention were applied in order to determine performance in the proposed sub-components. Their contribution for the prediction of performance in sustained attention tests and tests of higher cognitive abilities was assessed. The sub-components of the process model explained a large amount of variance in sustained attention tests, namely 55-74\%. More specifically, perceptual and mental operation speed were the strongest predictors, while there was a trend towards a small influence of motor speed on test performance. The measures of item shifting showed low reliabilities and did not predict test scores. In terms of discriminant validity, results of Study 1 indicated that the postulated sub-components were insufficient to explain a large amount of variance in working memory span tasks, in Study 2 the same was demonstrated for reasoning tasks. Altogether, the present study is the first to disentangle sub-components in sustained attention tests and to determine their role for test performance.
\end{abstract}

Keywords: sustained attention; concentration; process model; experimental test validation; processing speed; reasoning; working memory capacity

\section{Introduction}

Tests of sustained attention (sometimes also referred to as concentration) are among the most popular psychological tests in the domain of cognitive abilities and their validity has been demonstrated in numerous studies [1-5]. Yet, as the field of psychological assessment progresses, calls have been made to take a closer look into the processes that underly test scores and gain a deeper understanding of how these tests scores emerge [6-9]. For example, the new Standards for Educational and Psychological Testing request-in their first chapter-that validity evidence should not only be provided in terms of the test's internal structure or its relation to other measures, but also in terms of the involved response processes [10]. Regarding sustained attention tests, knowledge about the sub-components that drive performance in these tests would not only increase our understanding of sustained attention tests and what they measure, but it could also be the starting point to investigate well-documented but poorly understood phenomena like the large practice effects in sustained attention tests, respectively. Along these lines, the aim of the present study was to take a first step towards a process model of sustained attention tests. In the following, the construct as well as the characteristics of sustained attention tests are outlined and based on that, a process model comprising four sub-components is derived. 


\subsection{Sustained Attention Tests}

Sustained attention may be defined as the ability to achieve and maintain a cognitive state that is characterized by a continuous focus on the relevant task and constant mental effort or as Schweizer [11] (p. 46) put it "the long-term allocation of processing resources to a specific task demand". This ability is necessary for higher cognitive performances and for a large number of activities in everyday and professional life [12]. Not surprisingly, tests of sustained attention are among the most frequently used cognitive ability tests and they are applied in almost every psychological discipline from business to clinical to traffic psychology [3-5].

The first tests designed to measure sustained attention were cancellation and mental arithmetic tests and they even go back to the end of the 19th century [13]. Typically, in letter cancellation tests, rows of letters are presented simultaneously and the test-taker is required to look for target stimuli (for example, the letter " $a$ ") and cross out as many of them as possible until the test is over. Similarly, in mental arithmetic tests, many simple equations are presented at the same time and the participants are required to tick as many of the correct equations and to cross out as many of the incorrect equations as possible within a given time limit. The key performance index in these tests is the number of marked items (speed) or the number of correctly marked items (error-corrected speed) [3]. Modern sustained attention tests follow the tradition of these first tests and still use letter cancellation, mental arithmetic, sorting tasks, and other simple tasks [14].

Although stimuli and tasks may vary between different sustained attention tests, there are two main features that these tests have in common: First, the stimulus material and tasks are simple [14,15] and second, they share a characteristic presentation mode, i.e., several stimuli are presented simultaneously and participants are required to respond and deliberately shift between them until the test is over [15-17]. This so-called self-paced mode constitutes an integral feature of sustained attention tests, because it requires the test-taker to constantly stay on task until the test is over [15-17]. In contrast, other attention tests typically apply single stimuli and use fixed inter-stimulus (ISI) or response stimulus (RSI) intervals (also called force-paced mode). Therefore, self-paced sustained attention tests are considered to require higher mental effort, as the test-takers need to continuously allocate processing resources to the task, while force-paced attention tests allow them to take short breaks between successive items $[11,15,17,18]$.

However, while there is a common understanding of the essential features of sustained attention tests, to date, there is no formal model or systematic examination of the sub-components that may drive performance in these tests. It has also been stated that despite its vital role, sustained attention tends to be neglected in the field of cognitive abilities [18,19]. Therefore, in the present paper, we address this knowledge gap and propose and investigate a process model of sustained attention tests.

\subsection{A Process Model of Sustained Attention Tests}

Imagine a typical sustained attention test that, for example, requires continuous letter or symbol cancellation (e.g., the d2-R [1] or the Frankfurt Attention Inventory [20]) or mental arithmetics (e.g., the Pauli Test [21] or the Revision Test [22]) for a prolonged period of time. First of all, the stimuli need to be perceived and since sustained attention tests present many stimuli at the same time, they impose high perceptual demands [23]. Secondly, the item has to be solved. Although these item-solving processes are not identical for cancellation (e.g., stimulus discrimination and response selection) and mental arithmetic tasks (e.g., mental addition, comparison of solutions, response selection), both share a simplicity and clarity of the cognitive task and a simplicity of the required mental operation. Indeed, previous studies already showed that a variety of sustained attention tests, notwithstanding their differences, correlated highly and loaded on the same factor [2,3]. Thus, we believe it is justified to subsume the different item-solving processes under a common sub-component which we refer to as a simple mental operation. Thirdly, all of these tasks require the execution of some type of motor response (e.g., to tick off, cross out or click on an item) and finally, they demand the deliberate shifting to the next item. Consequently, the test takers' performance should depend on 1) how quickly the 
target is perceived (perceptual speed), 2) how quickly the correct reaction to an item is identified (speed of a simple mental operation), 3) how quickly the motor reaction is carried out (motor speed) and additionally, 4) how much time it takes to move on to the next item (item shifting speed; see also References [1,24]).

Previous studies already investigated some of these proposed sub-components: For example, earlier research demonstrated that the correlation between sustained attention and reasoning measures is partly due to what the authors called shared perceptual and discrimination processes [23]. Moreover, it was shown that motor speed played a role for performance in a variety of sustained attention tests $[3,22,25]$. Finally, the intentional, self-paced shifting between items has repeatedly been mentioned as an important process in these tests $[15-18,26]$. The purpose of the present study is to extend these findings by exploring the role of the four proposed sub-components for performance in sustained attention tests. Moreover, while we presume these sub-components to be the main predictors of performance in sustained attention tests, in the following, we argue that tests of higher cognitive abilities should require more and also more complex mental operations beyond the sub-components of our process model of sustained attention tests.

\subsection{Discriminant Validity: Processes in Higher Cognitive Abilities}

Sustained attention is typically regarded as a prerequisite of higher cognitive performances [12]. These more complex cognitive abilities like reasoning (considered the best indicator of $g$ [27]) or working memory capacity (purportedly involved in a wide range of complex intellectual abilities, see Reference [28] for a review) involve additional and also more complex sub-processes or as Hunt [29] (p. 457) put it " ... tests of intelligence ... seem to require the orchestration of several different functions". Sternberg [30] identified several component processes in analogical reasoning, involving encoding (perception and storage of attributes), inference (discovering and storage of the relation), mapping (discovering the relation between the first and the second half), application (of the analogy to each answer option), justification (determining the superior answer if none fits perfectly), and finally, a response. Thus, while speeded reasoning tasks also require the fast perception of an item and a quick motor reaction, they additionally demand complex, iterative mental operations not covered by our process model of sustained attention tests.

Similarly, tasks of working memory span demand additional cognitive processes beyond the proposed sub-components. These tasks require the processing of new information and the storage and retention of information (that is no longer present) at the same time [31-33], involving processes like rehearsal, maintenance, memory updating, and controlled memory search [33,34]. Hence, while these tasks of higher cognitive abilities share some of the proposed sub-components, they additionally demand more complex mental operations not included in our process model of sustained attention. We would therefore, in terms of discriminant validity, expect our sub-components to be insufficient to explain a large amount of variance in these tests.

\subsection{Aims of the Present Research}

The main objective of the present study was to provide and validate the proposed sub-components of sustained attention tests by firstly, assessing the speed in these sub-components and secondly, examining to what extent these sub-components predicted performance in conventional sustained attention tests. The inspection time task [35], which is considered to impose mainly perceptual demands [36-38], was selected as a measure of perceptual speed. To assess the speed of the item-solving process, a modified version of the $\mathrm{d} 2-\mathrm{R}$ test of sustained attention was created that allowed the measurement of reactions to single items. Additionally, the simple reaction time task was applied as a prototypical measure of motor speed [39-41]. Furthermore, in the modified d2, the response-stimulus interval between successive items was varied within subjects to assess item shifting. It was anticipated that shorter RSI, which require the test-taker to immediately shift between items, would impede performance compared to longer intervals [42,43]. 
We then specified a model in which the sub-components predicted performance in sustained attention tests as well as tests of higher cognitive abilities. It was expected that the speed in the four sub-components would be significantly related to performance in sustained attention tests, that is, the faster the test taker perceived, solved, responded to the item, and shifted towards the next item, the higher the test score. In contrast, in terms of discriminant validity, more complex cognitive abilities like reasoning or working memory capacity should involve additional and also more complex processes not covered by our process model of sustained attention tests [30,33]. Thus, we would expect the proposed sub-components to explain only a limited amount of variance in these tests.

\section{Study 1}

\subsection{Materials and Methods}

\subsubsection{Participants}

One-hundred-and-three undergraduates of the Philipps University of Marburg gave informed consent prior to taking part in the study, participated voluntarily, and received partial course credit in exchange. The mean age was 23 years $(S D=5.2$, range $=18-58)$ and the majority was female $(68 \%)$. Many studied psychology (43\%), followed by economics (11\%), educational sciences (11\%), and other subjects. They had a mean educational training of 3.5 semesters $(S D=1.7)$. The participants reported a normal or corrected-to-normal vision.

\subsubsection{Procedure}

Participants were tested in groups of two to five in a laboratory. Each test session took about four hours including three ten minutes breaks. First, a pre-experimental questionnaire, the inspection time task, the simple reaction time task, the modified version of the $\mathrm{d} 2$ and the Revision Test were applied. After a break, they were followed by the electronic version of the $\mathrm{d} 2-\mathrm{R}$ and three reasoning tasks. The second break was followed by three verbal sustained attention tasks, the simple reaction time task (second administration), the modified $\mathrm{d} 2$ (second administration), and three working memory span tasks. After the third and final break and irrelevant for the present study, further cognitive tests and a final questionnaire were administered.

\subsubsection{Measures}

Several cognitive tasks were applied to test the proposed process model of sustained attention tests. As the overall aim was to gain a better understanding of the processes involved in these tests, we applied three sustained attention tests, namely the d2-R [1], the Revision Test [22], and three verbal subtasks from the Berlin Intelligence Structure (BIS) Test [44] (sustained attention and processing speed, as measured in the BIS, are conceptually similar and have been shown to measure the same construct $[3,45])$. These tasks were selected based on recommendations by Schmidt-Atzert et al. [3] and covered figural, numerical, and verbal demands [3]. For the tasks that were selected or created to assess the speed in the proposed sub-components of sustained attention tests, the $\mathrm{d} 2-\mathrm{R}$ served as a template. For example, a modified $\mathrm{d} 2$ was applied to measure operation speed. Finally, due to their good psychometric properties, figural, numerical and verbal reasoning tasks of the Intelligence-Structure-Test 2000 R [46] and figural, numerical, and verbal complex span tasks [47] were selected as measures of discriminant validity.

\section{Conventional Sustained Attention Tests}

Test d2-R Electronic Version [1]. In the d2-R, the task was to select the letter " $\mathrm{d}$ " with two marks out of " $\mathrm{d}$ " $\mathrm{s}$ and " $\mathrm{p}$ " $\mathrm{s}$ with one to four marks. Fourteen computer pages were applied, each consisted of 60 letters and was presented for $20 \mathrm{~s}$ (4.40 $\mathrm{min}$ in total, plus instructions). The dependent variable was the number of correctly marked items minus the number of confusion errors (error-corrected speed). 
Revision Test [22]. In this paper-pencil test, the task was to quickly assess whether a simple equation was correct, to tick the item if it was and to struck it out if it was not. The tests consisted of 15 lines with 44 items and $30 \mathrm{~s}$ per line (7.30 $\mathrm{min}$ in total, plus instructions). The number of correctly marked equations was assessed.

Berlin Intelligence Structure (BIS) Tasks of Verbal Processing Speed [44]. Three paper-pencil tasks of the Berlin Intelligence Structure Test were administered to measure verbal sustained attention. The first task "classification of words" (CW) was to strike out as many plants as possible from a list of 100 words within $30 \mathrm{~s}$. In the second task "uncompleted words" (UW), 57 incomplete words were presented on a sheet of paper and the missing letters had to be filled in within $50 \mathrm{~s}$. In the third task "part-whole" (PW), a list of 60 words was presented for $40 \mathrm{~s}$ and words with a certain semantic relation (a word that was part of another, e.g., month and year) had to be marked. Performance indices were the number of correct responses.

Tasks Assessing the Sub-Components

Perceptual Speed: The Inspection Time Task. In this task, exposure time of a pi-shaped figure with two legs of markedly different lengths was shortened adaptively. Critically, this task was about the shortest exposure time necessary to perceive and correctly indicate which of the two lines was longer, not about reaction times. It is considered a primarily perceptual task and was therefore selected as a measure of perceptual speed [36-38]. The present version of the task was programmed in E-Prime 2.0 [48]. On each trial, a white fixation cross was displayed on a black screen (1000 ms). Then, a white Pi-shaped figure with a shorter $(3.5 \mathrm{~cm})$ and a longer $(4.5 \mathrm{~cm})$ leg was presented against a black background and afterwards covered by a backward mask (300 ms). Subjects indicated which leg was longer by pressing " $\mathrm{c}$ " (left index finger, the key was colored red) or " $\mathrm{m}$ " (right index finger, the key was colored green) on a German QWERTZ computer keyboard. Stimulus exposure time was varied using a staircase procedure, i.e., four correct responses led to a shortened exposure time while an incorrect response led to a prolonged exposure time. After three practice trials, the staircase procedure started with an exposure time of $157 \mathrm{~ms}$ and decreased or increased in steps of $66 \mathrm{~ms}$ (at the beginning) to $16.5 \mathrm{~ms}$ (as the experiment proceeded). The experiment ended after 15 reversals (i.e., exposure time which decreased before suddenly increased or vice versa) or 96 trials. The individual inspection time was assessed as the shortest exposure time of the stimulus to which the participant managed to correctly react to for four times in a row.

Mental Operation and Item Shifting Speed: The Modified d2. This task was programmed in E-Prime 2.0 [48]. In each trial, three letters were presented simultaneously until the participant made a response. The task was to decide whether there was a $\mathrm{d} 2$ among them and press " $\mathrm{m}$ " (right index finger, the key was colored green) for a target and " $\mathrm{c}$ " (left index finger, the key was colored red) for a nontarget on a German QWERTZ computer keyboard. The number of targets and nontargets was counterbalanced, as was the position of the $\mathrm{d} 2$ and the congruence of flanking stimuli (for targets, i.e., whether there were one, two or three d2). Altogether, the task comprised 432 experimental plus 10 practice trials (RSI of $500 \mathrm{~ms}$ ) and took about 20 minutes. Mean reaction times (RT) served as indicators of mental operation speed ${ }^{1}$. However, the modified $\mathrm{d} 2$ also required efficient perceptual and motor processes. Therefore, overlapping cognitive processes between the different indicators of the sub-components were taken into account when specifying structural equation models in the data analysis.

Critically, in the modified d2, the response-stimulus interval (RSI) was varied (blockwise to avoid sequential effects due to mixed RSI [49]) in order to assess item shifting speed. The first experimental block consisted of 18 stimuli and included an RSI of $1000 \mathrm{~ms}$. In the following blocks, the RSI was

1 Trials after an RSI of 4000 ms were excluded, because the prolonged RSI was introduced to represent an RSI which is so long that it does not further improve performance $[49,50]$. 
decreased in steps of $100 \mathrm{~ms}$ until it was 0 . The last experimental block used an RSI of $4000 \mathrm{~ms}$. From there, the pattern of RSI started all over again. It was expected that short RSI impede performance and that participants' reactions become faster and more accurate as the RSI gets longer $[42,43]$ until the ideal time interval is approached. From there, performance should not benefit from further extension of the RSI $[49,50]$. Our rationale for determining item shifting speed was that, due to this relationship between RSI and RT, fast reactions should have been preceded by a sufficiently long RSI. Therefore, as an estimator of the time needed for an item shift, the average of RSI preceding the fastest $30 \%$ of correct reactions was determined.

Motor Speed: A Simple Reaction Time (SRT) Task. Participants were instructed to press the button " $\mathrm{c}$ " (Block 1, 20 trials, left index finger, the key was colored red) and afterwards the button " $\mathrm{m}$ " (Block 2, 20 trials, right index finger, the key was colored green) as fast as possible as soon as a black dot $(2 \times 2 \mathrm{~cm})$ appeared on screen. The dot was presented until a response was made and the next dot appeared after $1000 \mathrm{~ms}(+/-100 \mathrm{~ms}$ jitter). Altogether, the SRT task consisted of 40 experimental plus 10 practice trials. Mean RT in the SRT task served as indicators of motor speed, because this task is considered a prototypical measure of motor performance [39-41]. However, it also imposes basic perceptual demands which will be taken into account in the data analysis.

\section{Divergent Validity: Reasoning and Working Memory Span Tasks}

I-S-T 2000 R Electronic Version [46]. Figural reasoning was assessed using the task "matrices". Participants had to discover the rule underlying the placement of three figures and choose the missing figure out of five response options. In the numerical reasoning task "number series", participants had to identify the underlying rule in a row of seven numbers and fill in the next number in line (time limit for both tasks: $10 \mathrm{~min}$ for 20 items). In the verbal reasoning task "verbal analogies", participants had to find the relation between two words and find a word that has a similar relation to the third word out of five response options (time limit: $7 \mathrm{~min}$ for 20 items). The dependent variable in each task was the number of correct responses.

Complex Span Tasks. Three complex span tasks were applied to assess working memory capacity: Operation span, reading span, and symmetry span [47]. These tasks were similarly structured: They started with a series of practice trials in which 1) a storage task, 2) a processing task, and 3) the combination of the storage and the processing task were practiced. Afterwards, the test trials started in which the storage and the processing tasks were combined. In order to force the participants to focus on the processing task and not only on the recall of the elements, the time for one processing task in the test trials was limited to 2.5 standard deviations of the mean time for a processing task in the practice trials. Additionally, participants received feedback of the percentage of the correctly answered processing tasks. They were informed that their data would only be used if at least $85 \%$ of the processing tasks were answered correctly.

In the "symmetry span" task, participants were presented with a set of figures that were either symmetrical or asymmetrical down the vertical axis. After each figure, a $4 \times 4$ matrix was shown and one square of this matrix was colored red. The position of the red square in the matrix had to be recalled at the end of the set. The numeric version of this group of tasks was an "operation span" task. Participants were presented with a set of arithmetic operations and the task was to judge whether an equation was correct or not. After each arithmetic operation, a letter was presented that had to be recalled at the end of the set. In the "reading span" task, participants were presented with a set of sentences and had to judge whether each sentence was sensible or not. After each sentence, a letter was presented that had to be recalled at the end of the set. Set sizes ranged from 3-5 in the symmetry span task and from 4-6 in the operation and reading spans tasks. Each set size was administered two times (six items comprising 30 symmetry-square, equation-letter or sentence-letter pairs, respectively). The absolute score for each of the three tasks was the number of trials that were recalled in the correct order and without error. 


\subsection{Data Preprocessing}

For the RT analysis of the modified d2, errors were excluded and based on the correct trials, z-values were calculated for each participant in each block; trials with a RT above $z=2.5$ and below $z=-2.5$ were discarded as outliers. The same cut-offs were applied in the SRT task. For the inspection time task, one participant who stated to have pressed the buttons randomly in the post-experimental questionnaire and whose inspection time was above $z=4$ was excluded. Regarding the modified $\mathrm{d} 2$, more than $30 \%$ of incorrect responses led to an exclusion of the participant's data in this task (one participant). For the working memory span task, participants whose accuracy in the processing tasks was below 85\% were excluded (see recommendations in Reference [47]; two participants for the verbal, numeric, and figural version).

\subsection{Analysis Strategy}

First, as a precondition to assess a potential item shifting component, it was investigated whether short response-stimulus intervals between successive stimuli indeed impeded performance compared to longer response-stimulus intervals as reported in earlier studies [42,43]. Additionally, the descriptive statistics and reliability of the sub-components and cognitive ability tasks were inspected. Finally, to assess the predictive power of the process model, we specified structural equation models in which the four sub-components of perceptual, mental operation, motor and item shifting speed predicted performance in the employed sustained attention tests (convergent validity) and in the reasoning and working memory tasks (discriminant validity).

\subsection{Results}

\subsubsection{Calculating an Indicator of Item Shifting Speed}

The relationship between RSI and RT is depicted in Figure 1. As expected, a repeated-measures ANOVA with the within-subjects factor RSI yielded a significant effect, $F(7.939,809.754)=55.810$, $p<.000, \eta^{2} p=.354^{2}$, indicating increasingly shorter RT as the RSI became longer.

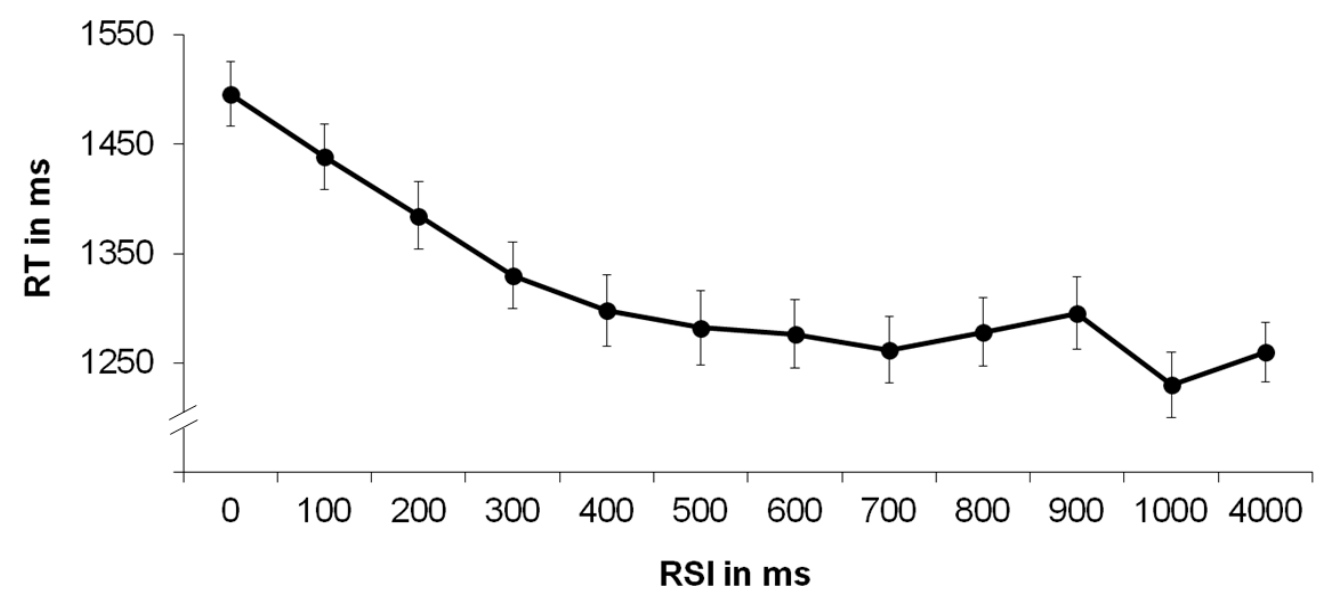

Figure 1. Mean reaction time (RT) (in ms) as a function of the duration of the response-stimulus interval (RSI) (in ms).

Post-hoc tests using the Bonferroni correction revealed that increasing the RSI from 0 to $100 \mathrm{ms,}$ from 100 to $200 \mathrm{~ms}$ and up until $300 \mathrm{~ms}$ elicited a significant decrease in RT, respectively $(p<.05)$. These results suggest that the length of the RSI influenced RT and that very short RSI impeded performance.

2 Mauchly's sphericity test indicated a violation of the sphericity assumption for the factor RSI $(\chi 2(65)=210.992, p<.001)$. Therefore, the Greenhouse-Geisser correction was used to adjust degrees of freedom for the main effect of RSI $(\varepsilon=0.722)$. 
This relationship between RSI and RT was utilized to determine the individual time necessary for an item shift by selecting the fastest $30 \%$ of reactions and calculating the average of the preceding RSI.

\subsubsection{Descriptive Statistics and Reliability}

Means, standard deviations, and reliability estimates of the study measures are presented in Table 1, the correlation matrix is presented in Appendix A. Reliability estimates were high for the modified d2 ( $r_{t t}=.89$ (in retest)- .99 (Cronbach's $\left.\alpha\right)$ ) but low for the SRT task $\left(r_{t t}=.55\right.$ (in retest) -60 $($ Cronbach's $\alpha)$ ) and poor for the indicator of item shifting speed $\left(r_{t t}=.41\right.$ (in retest) -.51 (Cronbach's $\alpha)$ ). All applied sustained attention tests showed good or excellent reliabilities $\left(r_{t t}=.80\right.$ (in retest) -.98 $($ Cronbach's $\alpha)$ ). Additionally, Cronbach's $\alpha$ for the reasoning and working memory span tasks ranged from low $\left(r_{t t}=.56\right)$ for figural working memory span) to very satisfactory $\left(r_{t t}=.90\right.$ for numerical reasoning).

Table 1. Means, standard deviations, and reliability estimates of the measures in Study 1.

\begin{tabular}{|c|c|c|c|}
\hline Tests/Scores & $M$ & $S D$ & $r_{t t}$ \\
\hline \multicolumn{4}{|l|}{ Speed in the Sub-Components } \\
\hline Inspection Time (perception) & $63.1^{\mathrm{a}}$ & 25.4 & - \\
\hline Reaction Time modified d2 (simple mental operation) & $1321.5^{\mathrm{a}}$ & 349.3 & $.89^{c} / .99^{\mathrm{d}}$ \\
\hline Simple Reaction Time (motor reaction) & $242.8^{\mathrm{a}}$ & 30.7 & $.55^{c} / .60^{d}$ \\
\hline Response-Stimulus Interval modified $d 2$ (item shifting) & $614.5^{\mathrm{a}}$ & 50.9 & $.41^{\mathrm{c}} / .51^{\mathrm{d}}$ \\
\hline \multicolumn{4}{|l|}{ Sustained Attention Tests } \\
\hline Figural (d2-R electronic version) & $222.4^{b}$ & 40.2 & $.98^{\mathrm{d}}$ \\
\hline Numerical (Revision Test) & $388.1^{b}$ & 66.7 & $.96^{\mathrm{d}}$ \\
\hline Verbal (BIS UW/CW/PW) & $31.0 / 22.7 / 12.6^{\mathrm{b}}$ & $7.1 / 6.3 / 2.7$ & $.96 / .93 / .80^{\mathrm{d}}$ \\
\hline \multicolumn{4}{|l|}{ Reasoning Tests } \\
\hline Figural (matrices, I-S-T 2000 R) & $10.5^{\mathrm{b}}$ & 3.0 & $.61^{\mathrm{d}}$ \\
\hline Numerical (number series, I-S-T 2000 R) & $13.2^{\mathrm{b}}$ & 5.1 & $.90^{\mathrm{d}}$ \\
\hline Verbal (verbal analogies, I-S-T 2000 R) & $11.5^{\mathrm{b}}$ & 2.9 & $.61^{\mathrm{d}}$ \\
\hline \multicolumn{4}{|l|}{ Working Memory Span Tasks } \\
\hline Figural (symmetry span) & $15.3^{\mathrm{b}}$ & 4.2 & $.56^{\mathrm{d}}$ \\
\hline Numerical (operation span) & $24.0^{\mathrm{b}}$ & 5.9 & $.74^{\mathrm{d}}$ \\
\hline Verbal (reading span) & $21.1^{\mathrm{b}}$ & 5.8 & $.67^{\mathrm{d}}$ \\
\hline
\end{tabular}

Notes: ${ }^{a}$ Average speed in $\mathrm{ms},{ }^{\mathrm{b}}$ Number of correct items (minus confusion errors for sustained attention tests),

c Retest reliability, ${ }^{\mathrm{d}}$ Cronbach's $\alpha$.

\subsubsection{Structural Equation Modeling}

The contribution of the subcomponents of perceptual, mental operation, motor and item shifting speed for the prediction of performance in sustained attention tests, reasoning and working memory span tasks was assessed using Amos 24.0 [51]. Prior to the structural equation modeling, missing values were imputed using the expectation-maximization (EM) algorithm [52].

For the modified $\mathrm{d} 2$ (mental operation speed), motor (simple reaction time task), and item shifting speed, trials were randomly assigned to one of three indicators, to assure identifiability of the model [53]. Regarding the adaptive inspection time task, since it cannot be spitted, the reliability estimates for adults as reported in a meta-analysis [54], $r_{t t}=.73$, was incorporated in the model via the error term [55]. All study measures were converted so that high values reflected better performance.

In the model, the modified $\mathrm{d} 2$ was regressed on perceptual speed (measured as inspection time) and motor speed (measured as simple reaction time) to account for shared perceptual and motor processes and to extract a residual of the modified $\mathrm{d} 2$ that would capture mental operation speed. Similarly, as the simple reaction time task, which was applied as a measure of motor speed, also imposed basic perceptual demands, it was regressed on perceptual speed (measured as inspection time) to derive a residual that would represent the sub-component of motor speed. Performance in the applied sustained attention, reasoning and working memory span tests was regressed on the so-obtained sub-components of perceptual, mental operation, motor and item shifting speed. 
Predicting Performance in Sustained Attention Tests

First of all, a model was specified to examine the sub-components' contribution for the prediction of performance in sustained attention tests. The model (see Figure 2) indicated a good fit $(\chi 2(56)=58.645, p=.379, \mathrm{RMSEA}=.022(.000, .066), \mathrm{CFI}=.997, \mathrm{SRMR}=.049)$ and the sub-components explained a large amount, namely $74 \%$, of sustained attention test variance. Perceptual and mental operation speed were the main predictors. Descriptively, there was a small influence of motor speed but it failed to reach significance $(p=.13)$. The indicator of item shifting speed did not predict performance.

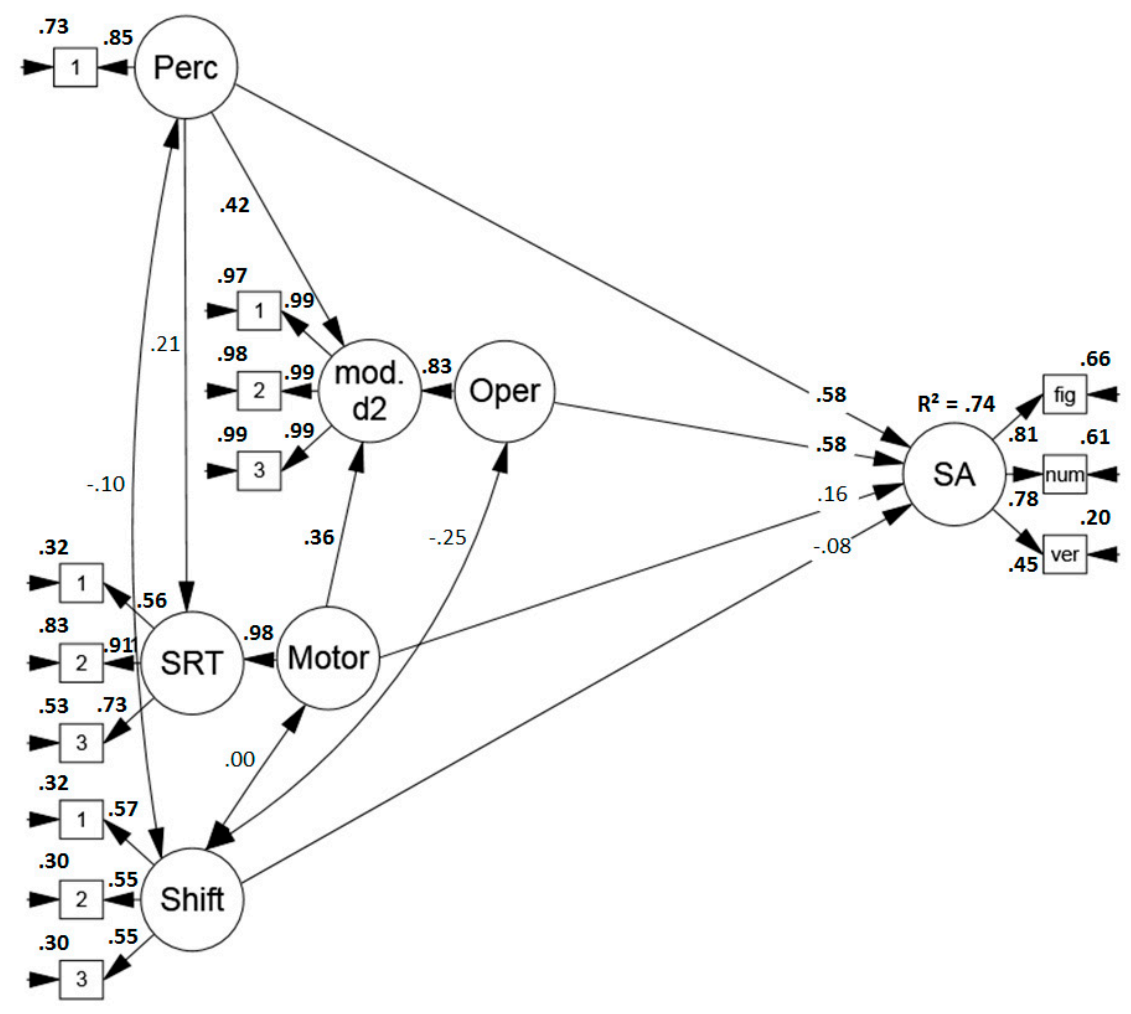

Figure 2. Standardized solution of the model predicting performance in sustained attention tests (convergent validity) based on the proposed process model of sustained attention tests. Significant results are printed in boldface. Perc $=$ perceptual speed, mod. $\mathrm{d} 2=$ modified $\mathrm{d} 2$, Oper. $=$ operation speed, SRT = simple reaction time task, Motor = motor speed, Shift = item shifting speed, SA = sustained attention, fig $=$ figural task, num $=$ numerical task, verb $=$ verbal task.

Predicting Performance in Sustained Attention, Reasoning and Working Memory Span Tasks

Secondly, the model was extended to assess the predictive power of the sub-components for performance in tests of higher cognitive abilities. The model (see Figure 3) revealed an acceptable to good fit $\left(\chi 2(132)=161.630, p=.386^{3}\right.$, RMSEA $=.047(.011, .070)$, CFI $=.974$, SRMR $\left.=.073\right)$. Surprisingly, the correlation between sustained attention and reasoning performance was higher than reported in earlier studies (for a meta-analysis, see Reference [56] which reports a mean correlation of $r=.29$ ). Moreover, unexpectedly, the process model predicted performance in reasoning tests well and explained $58 \%$ of the test variance. Not only perceptual speed, but also the speed of the relatively simple mental operation in the modified $\mathrm{d} 2$ was a good predictor of reasoning performance. Finally, as anticipated, the four sub-components explained only a modest amount of variance, namely $11 \%$ in working memory span performance.

3 The assumption of multivariate normality could not be confirmed (multivariate kurtosis $=37.441$, c.r. $=6.726, p<.001$ ). A Bollen-Stine bootstrap procedure (1000 samples) was conducted to obtain a corrected $p$-value for the $\chi 2$-test. 


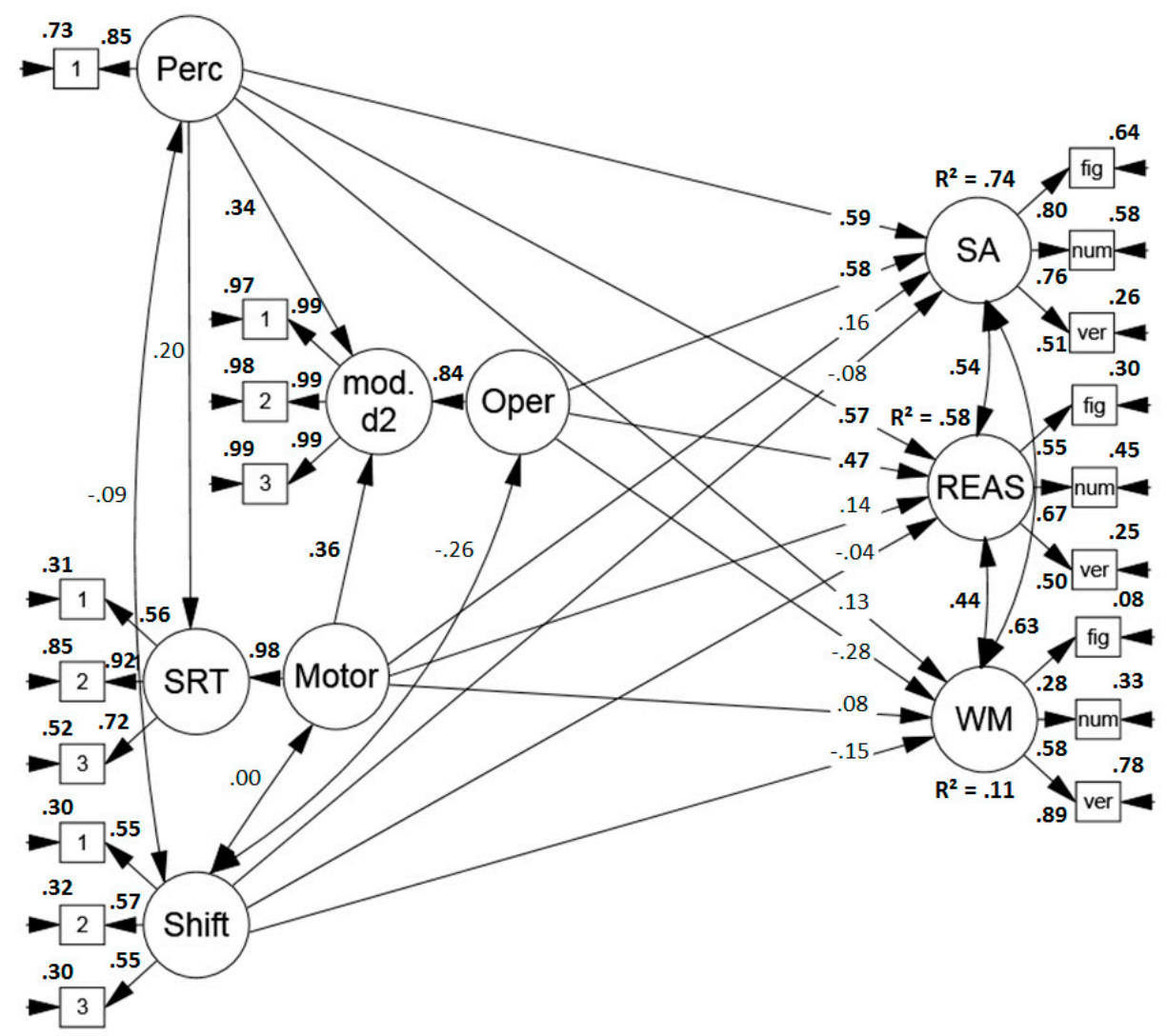

Figure 3. Standardized solution of the model predicting performance in sustained attention tests (convergent validity), reasoning, and working memory span tasks (discriminant validity) based on the proposed process model of sustained attention tests. Significant results are printed in boldface. Perc $=$ perceptual speed, mod. $\mathrm{d} 2=$ modified $\mathrm{d} 2$, Oper $=$ operation speed, $\mathrm{SRT}=$ simple reaction time task, Motor = motor speed, Shift = item shifting speed, SA = sustained attention, REAS = reasoning, $\mathrm{WM}=$ working memory span, fig = figural task, num = numerical task, verb = verbal task.

\subsection{Discussion}

In Study 1, individual differences in the sub-components explained $74 \%$, and thus, a large amount of variance in sustained attention tests. More specifically, two components, namely perceptual and mental operation speed showed to be strong predictors of test performance, while there was a small, but not significant $(p=.13)$ influence of motor speed.

Yet, it is conceivable that these results may partly be due to an overlap between the modified $\mathrm{d} 2$ and the $\mathrm{d} 2-\mathrm{R}$ test of sustained attention that served as one of the dependent variables. Therefore, another model was run in which only the Revision Test and the verbal subtasks of the BIS served as indicators of sustained attention test performance (see Figure 4). The model showed a sufficient to good fit $\left(\chi 2(115)=141.459, p=.358^{4}, \mathrm{RMSEA}=.047(.005, .072), \mathrm{CFI}=.975, \mathrm{SRMR}=.071\right)$. Altogether, the sub-components explained $68 \%$ of the variance in sustained attention performance and again, perceptual and mental operation speed were the strongest predictors. Thus, the explanatory power of the proposed process model for performance in sustained attention tests was not only due to an overlap between the applied tasks.

4 The assumption of multivariate normality could not be confirmed (multivariate kurtosis $=37.074$, c.r. $=6.444, p<.001$ ) . A Bollen-Stine bootstrap procedure (1000 samples) was conducted to obtain a corrected $p$-value for the $\chi 2$-test. 


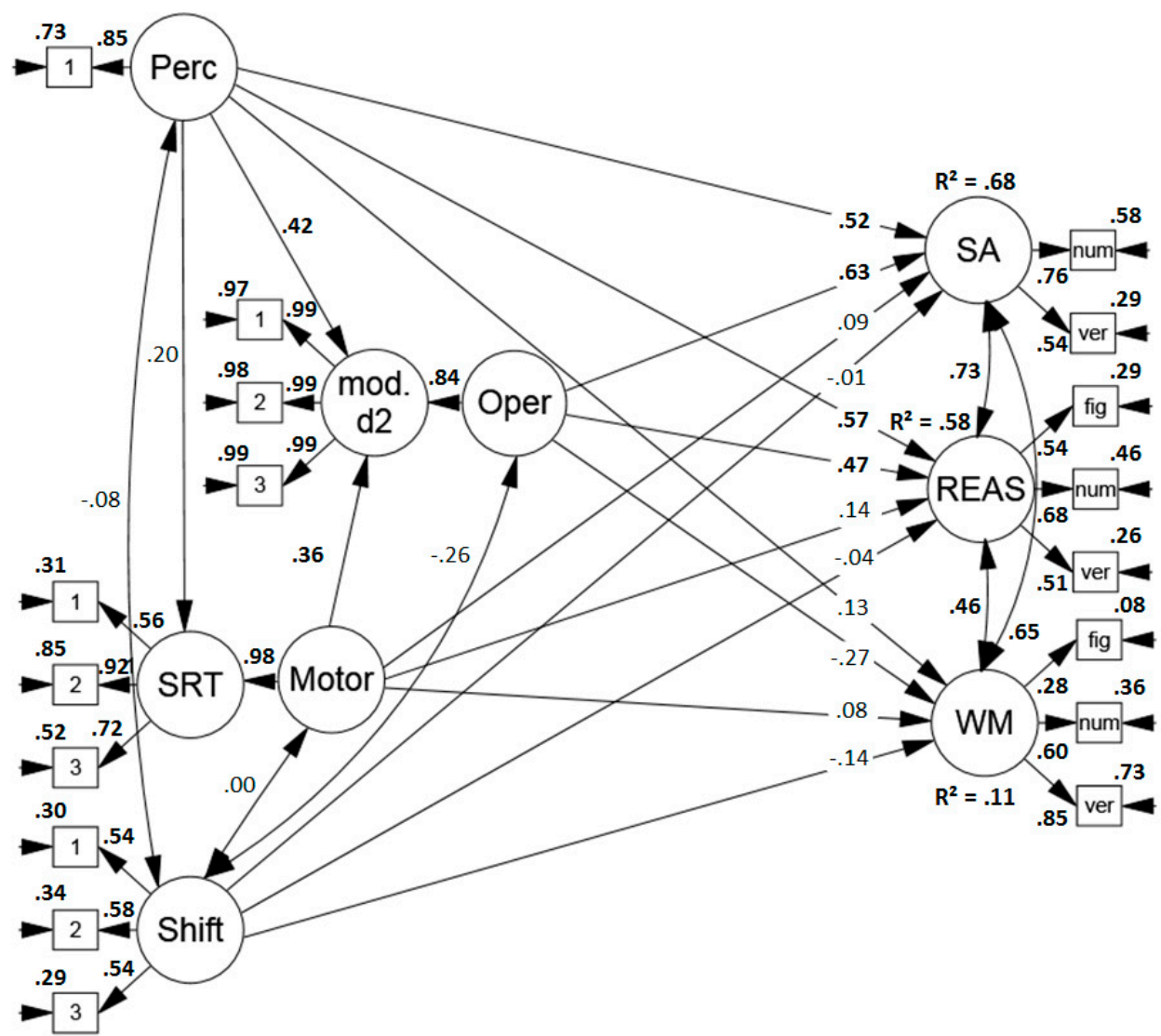

Figure 4. Standardized solution of the model predicting performance in sustained attention tests (convergent validity, without the $\mathrm{d} 2-\mathrm{R}$ as dependent variable), reasoning and working memory span tasks (discriminant validity) based on the proposed process model of sustained attention tests. Significant results are printed in boldface. Perc $=$ perceptual speed, mod. $\mathrm{d} 2=$ modified $\mathrm{d} 2$, Oper = operation speed, SRT = simple reaction time task, Motor = motor speed, Shift = item shifting speed, $\mathrm{SA}=$ sustained attention, REAS = reasoning, WM = working memory span, fig = figural task, num $=$ numerical task, verb = verbal task.

However, while it was demonstrated that the process model successfully predicted a large amount of variance in sustained attention tests, there was no relationship between item shifting speed and performance in sustained attention tests. On the one hand, this is surprising, as theoretical considerations and earlier research point towards a special significance of the self-paced presentation mode of sustained attention tests [5,15-17], which suggests that a test-taker who succeeds in the fast, deliberate shifting between items should also achieve a higher score in sustained attention tests. On the other hand, we did not succeed in reliably measuring this proposed sub-component with a retest-reliability of .41 and a split-half reliability of .51. We can think of two possible explanations for this: first, item shifting is a flexible process which varies from trial to trial, and thus, represents a state rather than a cognitive ability, or second, our operationalization and measurement of item shifting was inadequate. In order to examine the latter, we took a different approach to investigate item shifting in Study 2.

Moreover, the process model ex hypothesis failed to predict performance in working memory span tasks. However, regarding reasoning performance, not only perceptual speed but also mental operation speed explained a large amount of variance in these tests. While it was not surprising that perceptual processes played a role in reasoning tests (see also Reference [36]), there was the expectation that the simple mental operation required in sustained attention tests would be insufficient to account for the complex processes involved in reasoning. We identified two potential reasons for this finding: First, sustained attention and reasoning tests were unusually highly correlated $(r=.58)$ in the present 
study, whereas earlier studies reported moderate correlations between these cognitive abilities $[3,56]$. A reason for this high correlation might have been the relatively late administration (right after several sustained attention tests and more than one hour into the session) of the reasoning tests in the middle of a potentially exhausting, four-hour long test battery of cognitive ability tests. That means, the long test session might have changed the validity of the reasoning tests so that they captured sustained attention abilities especially well. Second, there is much evidence that the complexity of a task and thereby its correlation with reasoning increases with the number of relevant stimuli [57-59]. Therefore, the modified $\mathrm{d} 2$ with its three simultaneously relevant stimuli may have been too complex, and thus, might have become a good indicator of reasoning performance.

In Study 2, we address the main issues of Study 1 by (1) operationalizing the proposed item shifting ability differently, (2) presenting the reasoning tests at the beginning of the test battery, and (3) lowering the complexity of the modified $\mathrm{d} 2$ in order to measure mental operation speed more adequately.

\section{Study 2}

\subsection{Materials and Methods}

\subsubsection{Participants}

One hundred students (72\% female) voluntarily participated in Study 2 and received partial course credit in exchange. Their mean age was 22.9 years $(S D=4.6$, range $=18-40)$ and they had studied 3.2 semesters $(S D=2.4)$ on average in fields like psychology $(42 \%)$, educational sciences $(18 \%)$ or economics $(9 \%)$. Participants gave informed consent in accordance with the Declaration of Helsinki prior to participation.

\subsubsection{Procedure}

Each test session took about two hours including two ten-minute breaks. It started with a pre-experimental questionnaire, followed by three reasoning tasks. After a break, the inspection time task, the simple reaction time task, the modified $\mathrm{d} 2$ and the Revision Test were applied. After another break, the electronic version of the $\mathrm{d} 2-\mathrm{R}$ and the verbal sustained attention tests were administered, followed by a second exposure of the inspection time task, the simple reaction time task, the modified $\mathrm{d} 2$ and a final short questionnaire.

\subsubsection{Measures}

For the assessment of the sub-components of sustained attention tests, another modified $\mathrm{d} 2 \mathrm{was}$ created in order to overcome limitations of the first study. Thus, the assessment of mental operation speed and item shifting differed from Study 1 and is described below. Regarding the assessment of sustained attention and reasoning performance, the same tests were applied as in Study 1.

Tasks Assessing the Sub-Components

Mental Operation Speed and Item Shifting: The modified d2. Similarly, as in Study 1, the rationale for determining item shifting costs was that responses are faster and more accurate when the length of the RSI is appropriate, whereas too short RSI impede performance [42,43]. In Study 2, item shifting costs were determined as the difference in RT in the conditions with (force-paced) and without an RSI (self-paced).

In the modified version of the $\mathrm{d} 2$, the pace of the task was manipulated (force-paced vs. self-paced) and as part of another study, the stimulus arrangement was varied. In the first two blocks, one stimulus was presented at a time and participants had to decide whether the relevant letter was a d2 (response: " $\mathrm{m}$ ", right index finger) or not (response: " $\mathrm{c}$ ", left index finger). In Blocks 3 and 4, three stimuli were presented at a time, but only the one in the center was relevant. Critically, after the response, there was 
an RSI of 500 ms in Blocks 1 and 3 (force-paced conditions) and this RSI was removed in Blocks 2 and 4 (self-paced conditions). Each block consisted of 80 stimuli plus 10 practice trials ( $15 \mathrm{~min}$ in total).

Mean RT of the first two blocks of the modified d2 served as indicators of mental operation speed. As a measure of item shifting costs, the difference in RT of the conditions with (Block 1 and 3) and without an RSI (Block 2 and 4) was assessed. That means, we investigated individual differences in the extent to which RT increased as the participants were required to continuously react to stimuli (self-paced conditions) compared to conditions that included short breaks between successive stimuli (force-paced conditions).

\subsection{Data Preprocessing}

With regard to data cleaning, the same procedure and criteria were applied as in Study 1. For the inspection time task, three participants who mentioned difficulties with the task and whose inspection time was above $z=4$ were excluded. For the modified d2, accuracy below $70 \%$ in the task led to the exclusion of the participant's data (three participants).

\subsection{Analysis Strategy}

First, as a precondition to determine item shifting costs, it was assessed whether the self-paced mode, which required the deliberate shifting between items, impeded performance compared to the force-paced mode, which allowed short intervals between successive items. Additionally, the descriptive statistics of the study variables were inspected and it was examined whether they showed sufficient reliabilities. Finally, structural equation models were specified in which the four sub-components predicted performance in different sustained attention tests (convergent validity) and reasoning tests (discriminant validity).

\subsection{Results}

\subsubsection{Calculating an Indicator of Item Shifting Costs}

As a precondition for determining item shifting costs, it was assessed whether RT differed significantly between the force-paced and the self-paced blocks. This was confirmed, $t(96)=14.980$, $p<.001$, indicating longer RT in the self-paced blocks $(M=704 \mathrm{~ms}, S D=92.5)$ than in the force-paced blocks $(M=628 \mathrm{~ms}, S D=86.7)$. Individual item shifting costs were calculated by first log-transforming response latencies and then subtracting mean RT in the force-paced from mean RT in the self-paced blocks. Log-transformed differences between times equal ratios. We were interested in the individual's relative performance decline or improvement as a function of the self-paced vs. force-paced mode (see also References $[32,60])$.

\subsubsection{Descriptive Statistics and Reliability}

Table 2 provides means, standard deviations, and reliability estimates of the study variables. The correlations of the study measures are presented in Appendix B. Reliability was sufficient to high for RT measures of the modified d2 ( $r_{t t}=.68-.89$ (in retest), $r_{t t}=.92-.97$ (split-half)) and tests of sustained attention $\left(r_{t t}=.83-.98\right.$ (Cronbach's alpha)), but low for the inspection time task $\left(r_{t t}=.58\right.$ (in retest)), the SRT task $\left(r_{t t}=.57\right.$ (in retest) -.75 (split-half) ) and for item shifting costs $\left(r_{t t}=.46\right.$ (in retest) -.80 (split-half)). Cronbach's alpha was high for the numerical reasoning test $\left(r_{t t}=.83\right)$ and considerably lower for the figural $\left(r_{t t}=.57\right)$ and verbal $\left(r_{t t}=.75\right)$ reasoning task. 
Table 2. Means, standard deviations, and reliability estimates of the measures in Study 2.

\begin{tabular}{|c|c|c|c|}
\hline Tests/Scores & $M$ & $S D$ & $r_{t t}$ \\
\hline \multicolumn{4}{|l|}{ Modified d2 } \\
\hline Reaction Time force-paced, single stimuli & $634.0^{\mathrm{a}}$ & 95.5 & $.68^{c}-.94^{d}$ \\
\hline Reaction Time self-paced, single stimuli & $702.2^{\mathrm{a}}$ & 96.3 & $.74^{\mathrm{c}}-.92^{\mathrm{d}}$ \\
\hline Reaction Time $_{\text {force-paced, three stimuli }}$ & $622.6^{\mathrm{a}}$ & 85.0 & $.89^{c}-.95^{d}$ \\
\hline Reaction Time self-paced, three stimuli & $705.3^{\mathrm{a}}$ & 94.0 & $.85^{\mathrm{c}}-.97^{\mathrm{d}}$ \\
\hline \multicolumn{4}{|l|}{ Sub-Components } \\
\hline Inspection Time (perceptual speed) & $53.7^{\mathrm{a}}$ & 27.8 & $.58^{\mathrm{c}}$ \\
\hline Reaction Time mean single stimuli (simple mental operation) & $668.1^{\mathrm{a}}$ & 91.2 & $.74^{\mathrm{c}}-.96^{\mathrm{d}}$ \\
\hline Simple Reaction Time (motor speed) & $239.6^{\mathrm{a}}$ & 26.3 & $.57^{\mathrm{c}}-.75^{\mathrm{d}}$ \\
\hline Item shifting reaction time difference (pace) & 75.5 & 49.6 & $.46^{\mathrm{c}}-.80^{\mathrm{d}}$ \\
\hline \multicolumn{4}{|l|}{ Sustained Attention Tests } \\
\hline Figural (d2-R electronic version) & $220.1^{b}$ & 33.9 & $.98^{\mathrm{d}}$ \\
\hline Numerical (Revision-Test) & $390.0^{\mathrm{b}}$ & 74.0 & $.96^{\mathrm{d}}$ \\
\hline Verbal (BIS UW/CW/PW) & $34.8 / 25.2 / 14.9^{b}$ & $8.7 / 5.7 / 2.5$ & $.95 / .95 / .83^{\mathrm{d}}$ \\
\hline \multicolumn{4}{|l|}{ Reasoning Tests } \\
\hline Figural (matrices, I-S-T 2000R) & $11.4^{\mathrm{b}}$ & 2.9 & $.60^{\mathrm{d}}$ \\
\hline Numerical (number series, I-S-T 2000R) & $13.2^{b}$ & 4.2 & $.83^{\mathrm{d}}$ \\
\hline Verbal (verbal analogies, I-S-T 2000R) & $11.9^{b}$ & 3.1 & $.67^{\mathrm{d}}$ \\
\hline
\end{tabular}

Notes: ${ }^{a}$ Average speed in $\mathrm{ms},{ }^{b}$ Average number of correct items (minus confusion errors for sustained attention tests), ${ }^{\mathrm{c}}$ Retest reliability, ${ }^{\mathrm{d}}$ Cronbach's $\alpha$.

\subsubsection{Structural Equation Modeling}

For the modified $\mathrm{d} 2$ (mental operation speed), the simple reaction time task (motor speed), and item shifting, trials were randomly assigned to one of three indicators. Regarding the inspection time task, its retest-reliability in Study $2, r_{t t}=.58$, was incorporated in the model via the error term [55]. All study measures were converted so that high values reflected better performance.

\section{Predicting Sustained Attention}

First, it was assessed to what extent the sub-components predicted performance in the applied sustained attention tests. The model (see Figure 5) revealed a good fit $\left(\chi 2(56)=84.824, p=.156^{5}\right.$, RMSEA $=.072(.038, .102), \mathrm{CFI}=.970$, SRMR $=.079)$ and the sub-components predicted $68 \%$ of the variance in sustained attention tests. Perceptual and mental operation speed were the strongest predictors and there was a trend towards a minor influence of motor speed $(p=.08)$, whereas item shifting costs did not predict test scores.

5 The assumption of multivariate normality could not be confirmed (multivariate kurtosis $=34.188$, c.r. $=8.656, p<.001$ ). A Bollen-Stine bootstrap procedure (1000 samples) was conducted to obtain a corrected $p$-value for the $\chi 2$-test. 


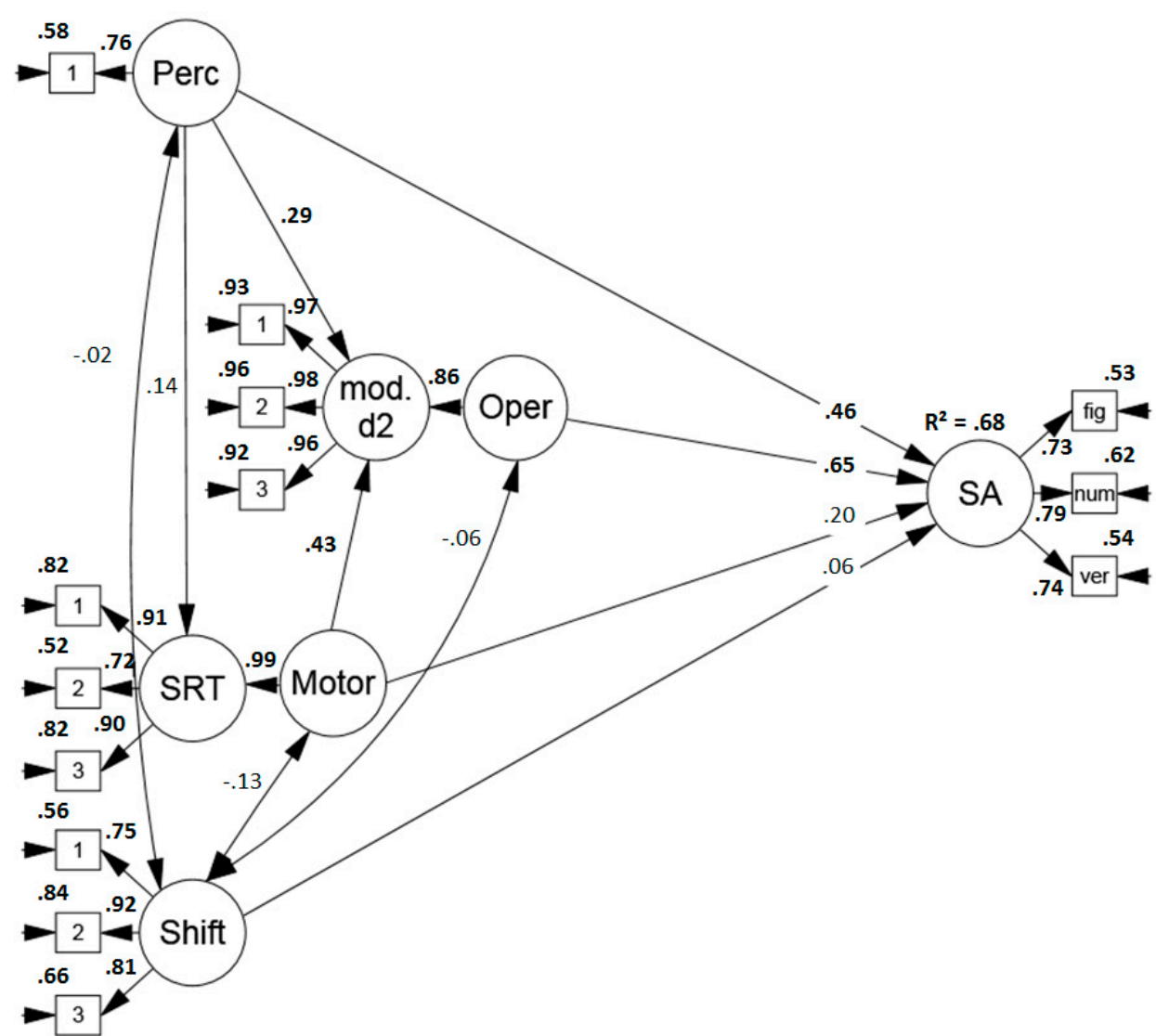

Figure 5. Standardized solution of the model predicting performance in sustained attention tests (convergent validity). Significant results are printed in boldface. Perc = perceptual speed, mod. $\mathrm{d} 2=$ modified d2, Oper $=$ operation speed, SRT $=$ simple reaction time task, Motor $=$ motor speed, Shift $=$ item shifting speed, $\mathrm{SA}=$ sustained attention, fig = figural task, num = numerical task, verb $=$ verbal task.

Predicting Sustained Attention and Reasoning Test Performance

Second, the model was extended to examine the sub-components' contribution for the prediction of performance in reasoning tasks. The model (see Figure 6) indicated an acceptable to good fit, $\left(\chi 2(90)=124.366, p=.197^{6}\right.$, RMSEA $=.062(.032, .087)$, CFI $=.967$, SRMR $\left.=.079\right)$. As expected, the process model explained a modest amount of variance in reasoning performance, namely $29 \%$, with perceptual speed being the strongest predictor.

6 The assumption of multivariate normality could not be confirmed (multivariate kurtosis $=25.676$, c.r. $=5.349, p<.001$ ) A Bollen-Stine bootstrap procedure (1000 samples) was conducted to obtain a corrected $p$-value for the $\chi 2$-test. 


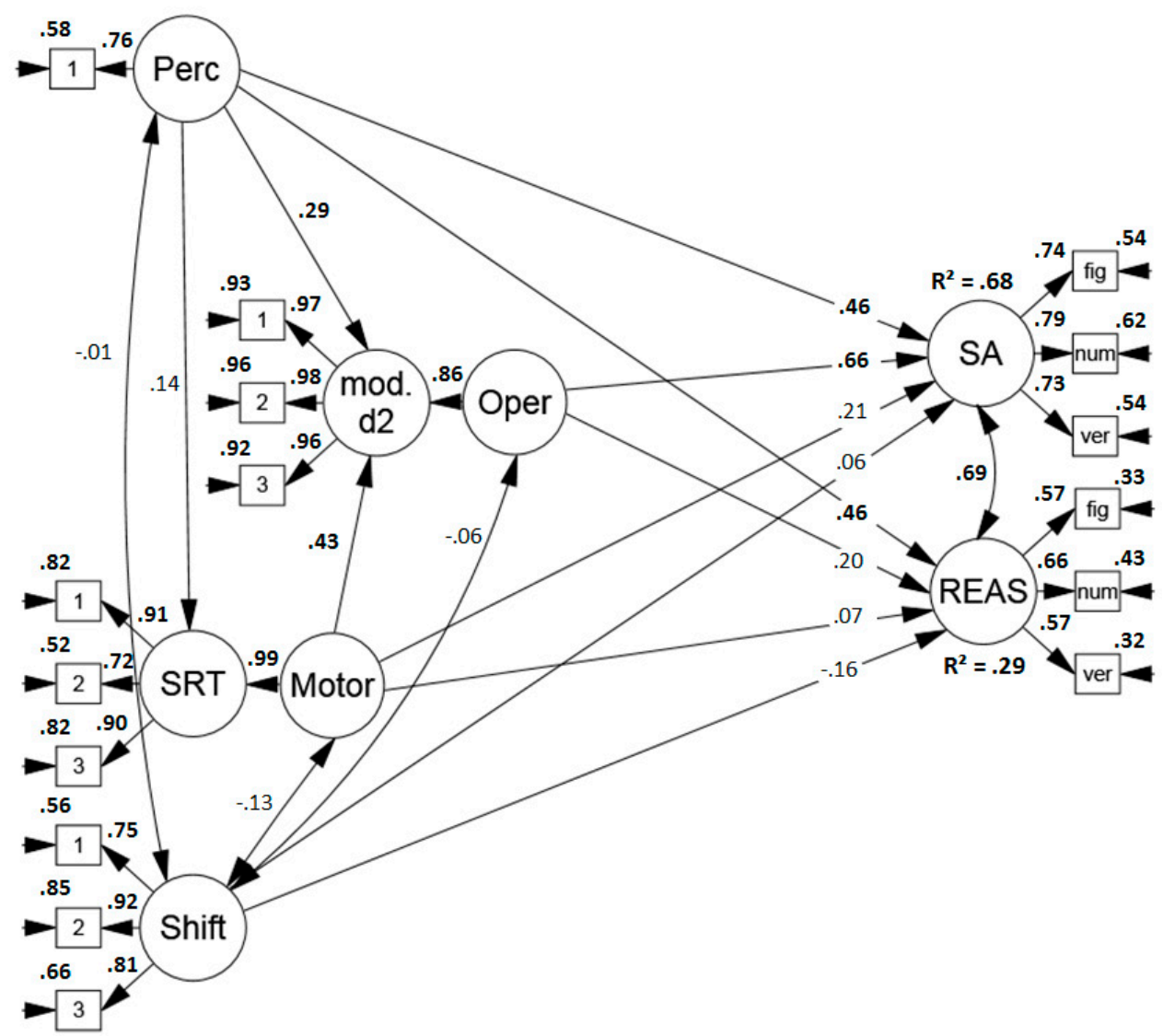

Figure 6. Standardized solution of the model predicting performance in sustained attention tests (convergent validity) and performance in reasoning tests (discriminant validity). Significant results are printed in boldface. Perc $=$ perceptual speed, mod. $\mathrm{d} 2=$ modified $\mathrm{d} 2$, Oper $=$ operation speed, $\mathrm{SRT}=$ simple reaction time task, Motor $=$ motor speed, Shift $=$ item shifting speed, SA = sustained attention, REAS = reasoning, fig = figural task, num = numerical task, verb = verbal task.

\subsection{Discussion}

Similarly, as in study 1 , the proposed sub-components revealed a high predictive value for performance in SA tests. Overall, the process model explained $68 \%$ of the variance in sustained attention tests. Similarly, as in Study 1, perceptual and mental operation speed were the strongest predictors and there was a trend towards a small influence of motor speed $(p=.08)$.

However, as the test material of the modified $\mathrm{d} 2$ and the $\mathrm{d} 2-\mathrm{R}$ test of sustained attention overlapped considerably, we conducted another analysis and excluded the $\mathrm{d} 2-\mathrm{R}$ test of sustained attention as the dependent variable (see Figure 7). Again, the model fit was good $(\chi 2(76)=94.676$, $\left.p=.349^{7}, \mathrm{RMSEA}=.050(.000, .080), \mathrm{CFI}=.981, \mathrm{SRMR}=.070\right)$. Altogether, the process model explained less but still a majority, namely $55 \%$ of the variance in sustained attention test performance. Still, perceptual and mental operation speed were the strongest predictors.

This time, we took another approach to operationalize item shifting by investigating item shifting costs, that is the decline in performance in a self-paced (without RSI) compared to a force-paced (with an RSI) condition of the modified d2. Although the reliability of the item shifting measure $\left(r_{t t}=.46\right.$ (in retest) -.80 (Cronbach's alpha)), was higher than in study $1\left(r_{t t}=.41\right.$ (in retest)- .51 (split-half)), it again failed to predict performance in sustained attention tests. Note though that RT difference scores are

7 The assumption of multivariate normality could not be confirmed (multivariate kurtosis $=24.943$, c.r. $=5.523, p<.001$ ). A Bollen-Stine bootstrap procedure (1000 samples) was conducted to obtain a corrected $p$-value for the $\chi 2$-test. 
typically lower in reliability than mean RT [61]. Overall, results are highly similar to Study 1 with the notable exception that, in accordance with our hypothesis, the process model explained a considerably smaller amount of variance in reasoning performance. In Study 2, only $29 \%$ of the variance in reasoning tests could be explained by the proposed process model, thus supporting discriminant validity of the postulated sub-components with regard to reasoning ability.

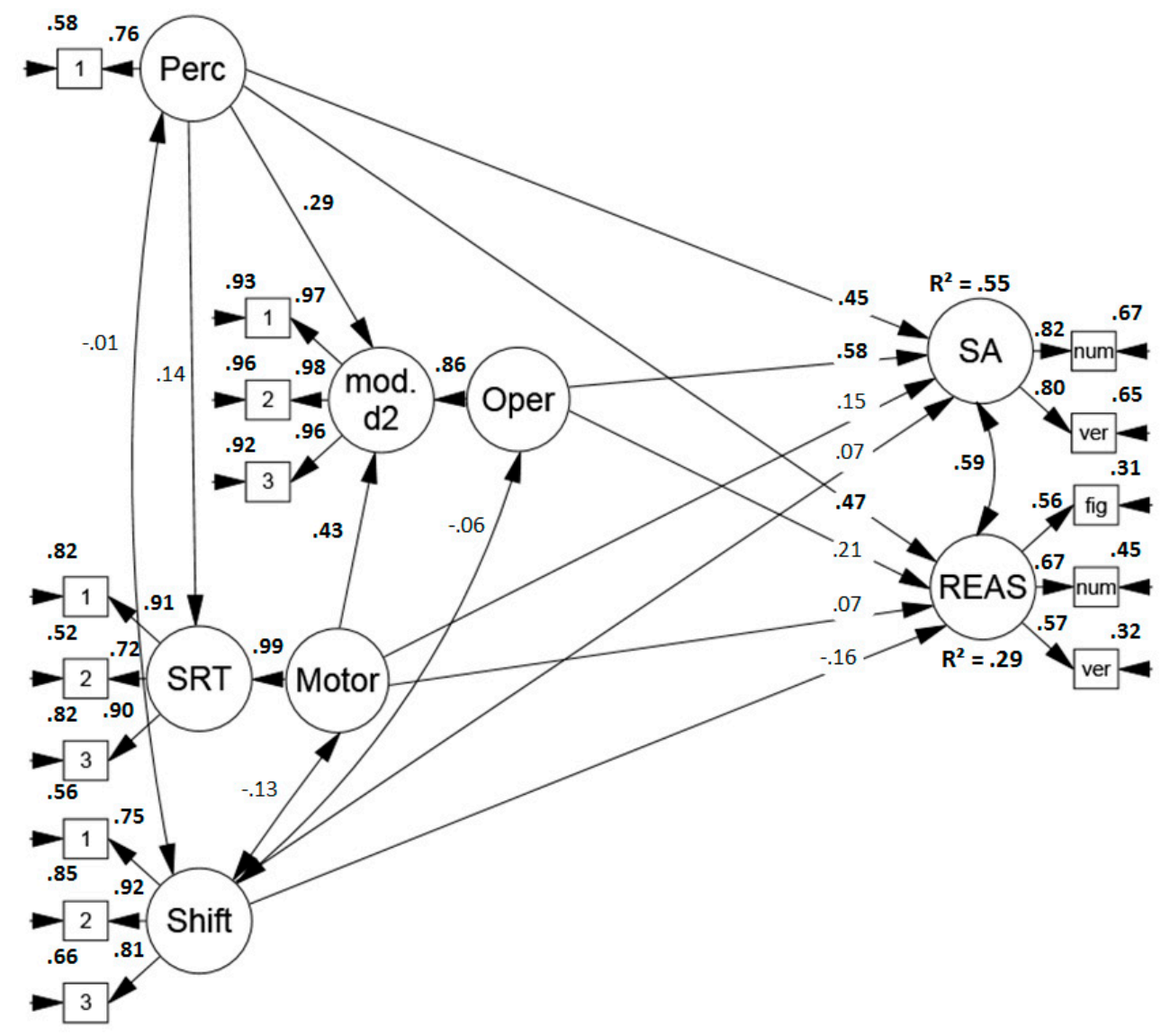

Figure 7. Standardized solution of the model predicting performance in sustained attention tests (convergent validity, without the $\mathrm{d} 2-\mathrm{R}$ as dependent variable) and performance in reasoning tests (discriminant validity). Significant results are printed in boldface. Perc = perceptual speed, mod. $\mathrm{d} 2=$ modified $\mathrm{d} 2$, Oper $=$ operation speed, SRT $=$ simple reaction time task, Motor $=$ motor speed, Shift = item shifting speed, SA = sustained attention, REAS = reasoning, fig = figural task, num $=$ numerical task, verb $=$ verbal task.

\section{General Discussion}

In the present study, a generic process model of sustained attention tests was provided based on earlier research on the characteristics of this group of tests. It comprises four essential sub-components: item perception, a simple mental operation, a motor response, and item shifting, hereby taking into account the variety of sustained attention tests. Furthermore, this model was validated by determining the speed in the proposed sub-components and it was demonstrated that two main sub-components, namely perceptual and mental operation speed, successfully predicted a large amount of variance in these tests. Moreover, regarding the third sub-component, motor speed, there was a trend towards a small influence on performance in sustained attention tests. In line with our expectations, the results indicate that while our process model predicted performance in sustained attention tests well, it was by and large insufficient to explain a large amount of variance in tasks of higher cognitive abilities like reasoning or working memory capacity. 


\subsection{The Role of the Sub-Components for Performance in Sustained Attention Tests}

Most importantly, the proposed process model was successful in predicting performance in sustained attention tests. In particular, perceptual and mental operation speed consistently showed to be strong predictors. This is not surprising, as the simultaneous presentation of many stimuli is a typical feature of these tests [16], which makes an efficient perception and processing especially beneficial. Moreover, a fast perception and processing allows a quick shift to the next item or even a preprocessing of the upcoming items [62]. Furthermore, there was a trend towards a small influence of motor speed on performance in both studies (Study 1: $p=.13$, Study 2: $p=.08$ ). Yet, the present sample was young and highly skilled in using computers, which could account for the small variance and low reliability of the measure in both studies [63]. Thus, the role of motor speed could possibly be larger for older participants or for participants who are less familiar with a computer keyboard [64]. Moreover, motor speed was assessed using a computerized task, but only one of the applied sustained attention tests was computerized-the electronic version of the d2-R. Hence, it is conceivable that motor speed as assessed in the current studies could not fully capture the motor processes required in paper-pencil tests. In line with this assumption, descriptively, the influence of motor speed on sustained attention test performance slightly dropped after the electronic $\mathrm{d} 2-\mathrm{R}$ was excluded from the structural equation models.

Unexpectedly, item shifting, assessed as item shifting speed in Study 1 and as item shifting costs in Study 2, did not predict performance in sustained attention tests. Theoretical considerations and earlier research $[16,17]$ pointed towards a special role of the self-paced presentation mode, indicating that the deliberate shifting from one item to another represents a characteristic demand of sustained attention tests. Indeed, in our two studies, whenever the test-takers were required to immediately shift from one item to another, performance was considerably impeded compared to conditions with longer intervals between successive items. However, the retest reliability of the applied item shifting measures was below .50 in both studies. This insufficiently low reliability could either be due to an inappropriate measurement or because item shifting represents a flexible and dynamic process, and thus, a state rather than a trait.

Finally, it is conceivable that the self-paced presentation mode affects several, possibly every sub-component involved when participants work through a test: Indeed, the self-paced mode demands a permanent deployment of mental effort and the enduring organization of the sub-components of sustained attention tests. This organization of sub-components, namely coordination, has repeatedly been suggested as a critical mechanism of sustained attention tests $[15,65,66]$. Moreover, it has successfully been extracted and its role for test performance has been demonstrated [66]. Therefore, the permanent deployment of mental effort in self-paced sustained attention tests could go along with an enhanced coordination demand which could likely have an impact on several sub-components beyond only the shifting from one item to another.

\subsection{Predicting Higher Cognitive Abilities}

It was expected that the proposed process model would be insufficient to explain a large amount of variance in more complex cognitive abilities like reasoning or working memory span, because they involve several additional processes [30,33]. In Study 1, it was demonstrated that the process model performed poorly in predicting test scores in working memory span tasks, confirming discriminant validity. This was in line with our expectations, as tests of working memory span measure the ability to store, maintain and retrieve information from working memory [31-33]. Thus, while they also involve perceptual and motor demands, speed in these processes should only be indirectly related to test performance.

Unexpectedly, in Study 1, the sub-components explained a substantial amount of variance in reasoning tests. While it was anticipated that perceptual processes play a role in these tests (see also References $[36,54]$ ) we expected the proposed process model to be insufficient to account for the complex mental operations required in reasoning tasks and hence, insufficient to explain a majority 
of variance in reasoning performance. We believe that this result is partly due to the comparatively complex task in the modified $\mathrm{d} 2$ and due to an unusually high correlation between sustained attention and reasoning tests in Study 1. This high correlation could have been caused by a late presentation of the reasoning tests in a four-hour long test session. Under such circumstances, the validity of the reasoning tests might have shifted from measures of reasoning to good indicators of sustained attention. In Study 2, in accordance with our expectations, the process model explained a comparatively small, but still robust amount of variance in reasoning performance. Again, perceptual speed showed to be a strong predictor of reasoning performance, while the influence of mental operation speed was much smaller. Furthermore, note that the factor loadings of the reasoning tasks on the reasoning factor were relatively low compared to the factor loadings of the sustained attention tests on the sustained attention factor, which led to an increased amount of explained variance for reasoning relative to sustained attention. Altogether, discriminant validity of the process model with regard to higher cognitive abilities could, by and large, be confirmed.

Beyond discriminant validity, the investigation of the relationship between the postulated sub-components and reasoning may also have implications for the study of the processes involved in reasoning performance, i.e., the tasks which are considered the best indicator of $\mathrm{g}$. In line with earlier influential research that related individual differences in the speed and efficiency of information processing to $g[27,36,67-70]$, we found consistent and substantial associations between perceptual speed and performance in reasoning tasks in both studies. Moreover, in Study 1, using a relatively complex modified d2 (including three simultaneously relevant stimuli), mental operation speed was a good predictor of reasoning performance, while the association between mental operation speed and reasoning was much smaller as a simpler modified $\mathrm{d} 2$ (presenting only one stimulus at a time) was applied in Study 2. A possible explanation could be that the more complex mental operations required in the first version of the modified $\mathrm{d} 2$ might have more effectively captured the (still much more complex) mental operations that are necessary to solve reasoning tasks (see also References [57-59]). However, note that, as discussed above, measures of reasoning and sustained attention were also unexpectedly highly correlated in that study.

\subsection{Limitations}

As mentioned earlier, the current samples were not representative with regard to education, age, and sex, as the samples consisted of highly educated, mostly female and young students. Thus, the results cannot be generalized to other samples; the same applies to other tests and tasks. With regard to sample size, a statistical power analysis with simulated data was conducted in Mplus [71]. For both studies, an $80 \%$ power to detect significant effects was given for relatively large effects (above .40). Therefore, we should not draw too strong a conclusion about the statistical significance of smaller or moderate effects. However, note that, beyond the significance level, the size of the effect as well as the amount of variance explained in the respective cognitive ability was of special interest in the current study.

Moreover, the correlation between sustained attention and reasoning tests was higher in the present samples than in earlier studies, which report moderate correlations (for a meta-analysis, see Reference [56] which reports a correlation of $r=.29$ ). Sustained attention tests have been shown to correlate higher with reasoning than other attention tests, which is interpreted in terms of higher cognitive demands due to a permanent mental effort [11,17]. Nevertheless, even with regard to other studies investigating the relationship between sustained attention and reasoning tests, the observed correlation was above comparative studies and samples. This could be attributed to the length of the test sessions, especially regarding the four-hour test session in Study 1 . Anyhow, test sessions in the reference studies were shorter but still several hours long, and thus, the observed result can only partly be attributed to the high endurance demand imposed by the long test session.

Finally, our approach of investigating individual differences in the postulated sub-components of sustained attention tests involved measures of perceptual, mental operation, motor and item shifting 
speed. However, these sub-components are not necessarily independent or strictly serial [72-74] and even relatively simple cognitive tasks include several of them [75]. Therefore, we specified regression models in order to account for shared variance between tasks with overlapping processes. Nevertheless, even using this approach, we might have not fully disentangled the shared processes between the indicators of the postulated sub-components.

\section{Conclusions}

The present study is, to the best of our knowledge, the first to propose and test a process model of sustained attention tests. In two studies, the convergent validity of the process model was demonstrated, while its discriminant validity with regard to higher cognitive abilities was by and large confirmed. It was demonstrated that two main sub-components, namely perceptual and mental operation speed explained a large amount of variance in sustained attention tests. Moreover, in both studies, there was a trend towards a small influence of motor speed on performance. However, a proposed sub-component of item shifting, which was introduced into the model in order to take the self-paced mode of these tests into account, could not be shown. Thus, for now, the impact of the self-paced mode on information processing in cognitive ability tasks remains to be elucidated. Altogether, the present paper may have taken an important first step towards a deeper understanding of the sub-components that drive sustained attention performance.

Author Contributions: I.B. and L.S.-A. conceived and designed the studies, I.B. programmed the tasks, analyzed the data and wrote the manuscript, L.S.-A. reviewed and edited the manuscript.

Funding: This research received no external funding.

Conflicts of Interest: The authors declare no conflict of interest. 


\section{Appendix A}

Table A1. Correlation matrix of the measures in Study 1.

\begin{tabular}{|c|c|c|c|c|c|c|c|c|c|c|c|c|c|c|}
\hline Tasks & 2. & 3. & 4. & 5. & 6. & 7. & 8. & 9. & 10. & 11. & 12. & 13. & 14. & 15. \\
\hline \multicolumn{15}{|l|}{ Sub-Components } \\
\hline 1. Inspection Time Task & $.35^{* *}$ & .19 & -.08 & $.45^{* *}$ & $.35^{* *}$ & .17 & $.22 *$ & .12 & $.34^{* *}$ & $.35^{* *}$ & .14 & $.24 *$ & .14 & .09 \\
\hline 2. Reaction Times modified d2 & & $.42 *$ & $-.24^{* *}$ & $.65^{* *}$ & $.64^{* *}$ & $.27^{* *}$ & $.25 *$ & $.27^{* *}$ & $.35^{* *}$ & $.47^{* *}$ & $.37^{* *}$ & .20 & .04 & -.14 \\
\hline 3. Simple Reaction Time & & & -.05 & $.26 *$ & .18 & .12 & $.20 *$ & .12 & $.26 *$ & .17 & .19 & .17 & .04 & .05 \\
\hline 4. Item Shifting Speed & & & & $-.30 * *$ & $-.14^{* *}$ & -.03 & -.07 & $-.18 *$ & -.02 & -.11 & -.05 & -.01 & -.00 & .08 \\
\hline \multicolumn{15}{|l|}{ Sustained Attention } \\
\hline 5. $\mathrm{d} 2-\mathrm{R}$ (electronic version) & & & & & $.62^{* *}$ & $.21^{*}$ & $.32 * *$ & $.33^{* *}$ & $.37^{* *}$ & $.43^{* *}$ & $.27^{* *}$ & $.29^{* *}$ & .17 & .18 \\
\hline 6. Revision Test & & & & & & $.24 *$ & $.35^{* *}$ & $.42 * *$ & $.27^{* *}$ & $.50^{* *}$ & $.25 *$ & .17 & .17 & .08 \\
\hline 7. BIS CW & & & & & & & $.57^{* *}$ & $.42^{* *}$ & $.28^{* *}$ & .11 & $.39^{* *}$ & .06 & .16 & $.27^{* *}$ \\
\hline 8. BIS PW & & & & & & & & $.47^{* *}$ & $.40^{* *}$ & $.41^{* *}$ & $.36^{* *}$ & $.23 *$ & $.22 *$ & $.32 * *$ \\
\hline 9. BIS UW & & & & & & & & & $.22 *$ & $.20 *$ & $.26^{* *}$ & .11 & .06 & $.20 *$ \\
\hline \multicolumn{15}{|l|}{ Reasoning } \\
\hline 10. I-S-T 2000 R Matrices & & & & & & & & & & $.37 * *$ & $.31 * *$ & .08 & .17 & .13 \\
\hline 11. I-S-T 2000 R Number Series & & & & & & & & & & & $.32 * *$ & $.23 *$ & .14 & .07 \\
\hline 12. I-S-T 2000 R Analogies & & & & & & & & & & & & $.25 *$ & .18 & .19 \\
\hline \multicolumn{15}{|l|}{ Working Memory Span } \\
\hline 13. Figural Span & & & & & & & & & & & & & $.24 *$ & $.22 *$ \\
\hline 14. Numerical Span & & & & & & & & & & & & & & $.48^{* *}$ \\
\hline 15. Verbal Span & & & & & & & & & & & & & & \\
\hline
\end{tabular}

Notes: $N=100-103$, due to excluded data in some tasks (pairwise deletion). ${ }^{*} p<.05,{ }^{* *} p<.01$. 


\section{Appendix B}

Table A2. Correlation matrix of the measures in Study 2.

\begin{tabular}{|c|c|c|c|c|c|c|c|c|c|c|c|}
\hline Tasks & 2. & 3. & 4. & 5. & 6. & 7. & 8. & 9. & 10. & 11. & 12. \\
\hline \multicolumn{12}{|l|}{ Sub-Components } \\
\hline 1. Inspection Time Task & $.26 *$ & .11 & .01 & $.26^{*}$ & $.34^{* *}$ & .20 & $.24 *$ & .17 & .17 & $.28^{* *}$ & .16 \\
\hline 2. Reaction Time modified $d 2$ & & $.44^{* *}$ & -.12 & $.68^{* *}$ & $.56^{* *}$ & $.43^{* *}$ & $.42 * *$ & $.39 * *$ & .04 & $.43^{* *}$ & .08 \\
\hline 3. Simple Reaction Time & & & -.12 & $.28^{* *}$ & $.25 *$ & .10 & .04 & .17 & .01 & .13 & .20 * \\
\hline 4. Item Shifting Costs & & & & .00 & -.02 & -.10 & .07 & .04 & -.08 & -.14 & -.02 \\
\hline \multicolumn{12}{|l|}{ Sustained Attention } \\
\hline 5. $\mathrm{d} 2-\mathrm{R}$ (electronic version) & & & & & $.57^{* *}$ & $.41^{* *}$ & $.26^{* *}$ & $.41 * *$ & $.23 *$ & $.39^{* *}$ & $.21 *$ \\
\hline 6. Revision Test & & & & & & $.56^{* *}$ & $.47^{* *}$ & $.57^{* *}$ & $.25 *$ & $.45^{* *}$ & .28 ** \\
\hline 7. BIS CW & & & & & & & $.51^{* *}$ & $.62 * *$ & $.23 *$ & $.36 * *$ & $.30 * *$ \\
\hline 8. BIS PW & & & & & & & & $.38^{* *}$ & .10 & $.24 *$ & .10 \\
\hline 9. BIS UW & & & & & & & & & .18 & $.35^{* *}$ & $.32 * *$ \\
\hline \multicolumn{12}{|l|}{ Reasoning } \\
\hline 10. I-S-T 2000 R Matrices & & & & & & & & & & $.35^{* *}$ & $.44^{* *}$ \\
\hline 11. I-S-T 2000 R Number Series & & & & & & & & & & & .33 ** \\
\hline 12. I-S-T 2000 R Analogies & & & & & & & & & & & \\
\hline
\end{tabular}

Notes: $N=94-100$, due to excluded data in some tasks (pairwise deletion). ${ }^{*} p<.05,{ }^{* *} p<.01$. 


\section{References}

1. Schmidt-Atzert, L.; Brickenkamp, R. Test d2-R-Elektronische Fassung des Aufmerksamkeits-und Konzentrationstests d2-R; Hogrefe: Göttingen, Germany, 2017.

2. Mirsky, A.F.; Anthony, B.J.; Duncan, C.C.; Ahearn, M.B.; Kellam, S.G. Analysis of the elements of attention: A neuropsychological approach. Neuropsychol. Rev. 1991, 2, 109-145. [CrossRef] [PubMed]

3. Schmidt-Atzert, L.; Bühner, M.; Enders, P. Messen Konzentrationstests Konzentration? Eine Analyse der Komponenten von Konzentrationsleistungen. Diagnostica 2006, 52, 33-44. [CrossRef]

4. Moosbrugger, H.; Goldhammer, F. Aufmerksamkeits- und Konzentrationsdiagnostik. In Leistung und Leistungsdiagnostik; Schweizer, K., Ed.; Springer: Heidelberg, Germany, 2006; pp. 83-102.

5. Westhoff, K.; Kluck, M.L. Ansätze einer Theorie konzentrativer Leistungen. Diagnostica 1984, 30, 167-183.

6. Bornstein, R.F. Toward a process-focused model of test score validity: Improving psychological assessment in science and practice. Psychol. Assess. 2011, 23, 532-544. [CrossRef] [PubMed]

7. Borsboom, D.; Mellenbergh, G.J.; Van Heerden, J. The concept of validity. Psychol. Rev. 2004, 111, $1061-1071$. [CrossRef] [PubMed]

8. Krumm, S.; Hüffmeier, J.; Lievens, F. Experimental test validation: Examining the path from test elements to test performance. Eur. J. Psychol. Assessment. Adv. Online Publ. 2017. [CrossRef]

9. Embretson, S.E. Construct validity: Construct representation versus nomothetic span. Psychol. Bull. 1983, 93, 179-197.

10. American Educational Research Association; American Psychological Association; National Council on Measurement in Education. Standards for Educational and Psychological Testing; American Educational Research Association: Washington, DC, USA, 2014.

11. Schweizer, K. An overview of research into the cognitive basis of intelligence. J. Individ. Differ. 2005, 26, 43-51. [CrossRef]

12. Lezak, M.D. Neuropsychological Assessment, 3rd ed.; Oxford University Press: New York, NY, USA, 1995.

13. Bartenwerfer, H. Allgemeine Leistungstests. In Handbuch der Psychologie, Band VI, Psychologische Diagnostik; Heiss, R., Ed.; Hogrefe: Göttingen, Germany, 1964; pp. 385-410.

14. Büttner, G.; Schmidt-Atzert, L. Diagnostik von Konzentration und Aufmerksamkeit; Hogrefe: Göttingen, Germany, 2004.

15. Westhoff, K.; Hagemeister, C. Konzentrationsdiagnostik; Pabst: Lengerich, Germany, 2005.

16. Krumm, S.; Schmidt-Atzert, L.; Eschert, S. Investigating the structure of attention: How do test characteristics of paper-pencil sustained attention tests influence their relationship with other attention tests? Eur. J. Psychol. Assess. 2008, 24, 108-116. [CrossRef]

17. Krumm, S.; Schmidt-Atzert, L.; Schmidt, S.; Zenses, E.M.; Stenzel, N. Attention tests in different stimulus presentation modes. J. Individ. Differ. 2012, 33, 146-159. [CrossRef]

18. Schweizer, K.; Moosbrugger, H. Attention and working memory as predictors of intelligence. Intelligence 2004, 32, 329-347. [CrossRef]

19. Beckmann, J.; Strang, H. Konzentration: Überlegungen zu einem vernachlässigten Konstrukt. In Aufmerksamkeit und Energetisierung. Facetten von Konzentration und Leistung; Hogrefe: Göttingen, Germany, 1993; pp. 11-32.

20. Moosbrugger, H.; Oehlschlägel, J. Frankfurter Aufmerksamkeits-Inventar (FAIR); Hogrefe: Göttingen, Germany, 1996.

21. Arnold, W. Der Pauli-Test; 5. Auflage; Springer: Berlin, Germany, 1975.

22. Marschner, G. Revisions-Test; Hogrefe: Göttingen, Germany, 1980.

23. Schweizer, K.; Zimmermann, P.; Koch, W. Sustained attention, intelligence, and the crucial role of perceptual processes. Learn. Individ. Differ. 2000, 12, 271-286. [CrossRef]

24. Sanders, A.F. Towards a model of stress and human performance. Acta Psychol. 1983, 53, 61-97. [CrossRef]

25. Schmidt-Atzert, L.; Bühner, M. Was misst der d2-Test? Eine experimentelle Analyse von Testleistungen. Diagnostica 1997, 43, 314-326.

26. Van Breukelen, G.J.P.; Roskam, E.E.C.I.; Eling, P.A.T.M.; Jansen, R.W.T.L.; Souren, D.A.P.B.; Ickenroth, J.G.M. A model and diagnostic measures for response time series on tests of concentration: Historical background, conceptual framework, and some applications. Brain Cognit. 1995, 147-179. [CrossRef] 
27. Carroll, J.B. Human Cognitive Abilities: A Survey of Factor-Analytic Studies; Cambridge University Press: New York, NY, USA, 1993.

28. Conway, A.R.A.; Kane, M.J.; Bunting, M.F.; Hambrick, D.Z.; Wilhelm, O.; Engle, R.W. Working memory span tasks: A methodological review and user's guide. Psychon. Bull. Rev. 2005, 12, 769-786. [CrossRef] [PubMed]

29. Hunt, E. Intelligence as an information processing concept. Br. J. Psychol. 1980, 71, 449-474. [CrossRef] [PubMed]

30. Sternberg, R.J. Component processes in analogical reasoning. Psychol. Rev. 1977, 84, 353-378. [CrossRef]

31. Daneman, M.; Carpenter, P. Individual differences in working memory and reading. J. Verbal Learn. Verbal Behav. 1980, 19, 450-466. [CrossRef]

32. Oberauer, K.; Süß, H.; Wilhelm, O.; Wittman, W. The multiple faces of working memory: Storage, processing, supervision, and coordination. Intelligence 2003, 31, 167-193. [CrossRef]

33. Unsworth, N.; Engle, R.W. On the division of short-term and working memory: An examination of simple and complex span and their relation to higher order abilities. Psychol. Bull. 2007, 133, 1038-1066. [CrossRef] [PubMed]

34. Unsworth, N.; Engle, R.W. A temporal-contextual retrieval account of complex span: An analysis of errors. J. Mem. Lang. 2006, 54, 346-362. [CrossRef]

35. Vickers, D.; Smith, P.L. The rationale for the inspection time index. Pers. Individ. Dif. 1986, 7, 609-623. [CrossRef]

36. Brand, C.R.; Deary, I.J. Intelligence and "Inspection Time.". In A Model of Intelligence; Eysenck, H., Ed.; Springer: New York, NY, USA, 1982; pp. 133-148.

37. Schweizer, K.; Koch, W. Perceptual processes and cognitive ability. Intelligence 2003, 31, 211-235. [CrossRef]

38. Vickers, D.; Nettelbeck, T.; Willson, R.J. Perceptual indices of performance: The measurement of 'Inspection Time' and 'Noise' in the visual system. Perception 1972, 1, 263-295. [CrossRef] [PubMed]

39. Ackerman, P.L. Determinants of individual differences during skill acquisition: Cognitive abilities and information processing. J. Exp. Psychol. Gen. 1988, 117, 288-318. [CrossRef]

40. Fleishman, E.A.; Hempel, W.E. Changes in factor structure of a complex psychomotor test as a function of practice. Psychometrika 1954, 19, 239-252. [CrossRef]

41. Sternberg, S.; Monsell, S.; Knoll, R.L.; Wright, C.E. The Latency and Duration of Rapid Movement Sequences: Comparisons of Speech and Typewriting. In Information Processing in Motor Control and Learning; Stelmach, G.E., Ed.; Academic Press: New York, NY, USA, 1978; pp. 117-152.

42. Jentzsch, I.; Dudschig, C. Why do we slow down after an error? Mechanisms underlying the effects of posterror slowing. Q. J. Exp. Psychol. 2009, 62, 209-218. [CrossRef]

43. Rabbitt, P. Psychological refractory delay and response-stimulus interval duration in serial, choice-response tasks. Acta Psychol. 1969, 30, 195-219. [CrossRef]

44. Jäger, A.O.; Süß, H.M.; Beauducel, A. Berliner Intelligenzstruktur-Test (BIS); Hogrefe: Göttingen, Germany, 1997.

45. Krumm, S.; Schmidt-Atzert, L.; Michalczyk, K.; Danthiir, V. Speeded paper-pencil sustained attention and mental speed tests. J. Individ. Differ. 2008, 29, 205-216. [CrossRef]

46. Liepmann, D.; Beauducel, A.; Brocke, B.; Amthauer, R. Intelligenz-Struktur-Test 2000 R; Hogrefe: Göttingen, Germany, 2007.

47. Oswald, F.L.; McAbee, S.T.; Redick, T.S.; Hambrick, D.Z. The development of a short domain-general measure of working memory capacity. Behav. Res. Methods 2014, 47, 1343-1355. [CrossRef] [PubMed]

48. Schneider, W.; Eschman, A.; Zuccolotto, A. E-Prime 2.0 Software; Psychology Software Tools Inc.: Pittsburgh, PA, USA, 2002.

49. Niemi, P.; Näätänen, R. Foreperiod and simple reaction time. Psychol. Bull. 1981, 89, 133-162. [CrossRef]

50. Frowein, H.W.; Sanders, A.F. Effects of visual stimulus degradation, S-R compatibility, and foreperiod duration on choice reaction time and movement time. Bull. Psychon. Soc. 1978, 12, 106-108. [CrossRef]

51. Airbuckle, J.L. Amos (Version 24.0); IBM SPSS: Chicago, IL, USA, 2016.

52. Allison, P.D. Missing Data; Sage Publications: Thousand Oaks, CA, USA, 2001.

53. Anderson, J.; Gerbing, D. Structural equation modeling in practice: A review and recommended two-step approach. Psychol. Bull. 1988, 103, 411-423. [CrossRef]

54. Kranzler, J.H.; Jensen, A.R. Inspection time and intelligence: A meta-analysis. Intelligence 1989, 13, 329-347. [CrossRef] 
55. Brown, T.A. Confirmatory Factor Analysis for Applied Research; The Guilford Press: New York, NY, USA, 2006.

56. Schmidt-Atzert, L.; Bühner, M. Aufmerksamkeit und Intelligenz. In Intelligenz und Kognition: Die kognitiv-biologische Perspektive der Intelligenz; Schweizer, K., Ed.; Verlag Empirische Pädagogik: Landau, Germany, 2000; pp. 125-151.

57. Jensen, A.R. Reaction Time and Psychometric g. In A Model for Intelligence; Eysenck, H.J., Ed.; Springer: Berlin, Germany, 1982; pp. 93-132.

58. Jensen, A.R. The g beyond Factor Analysis. In The Influence of Cognitive Psychology on Testing; Ronning, R.R., Glover, J.A., Conoley, J.C., Witt, J.C., Eds.; Erlbaum: Hillsdale, NJ, USA, 1987; pp. 87-142.

59. Vernon, P.A. The g-loading of intelligence tests and their relationship with reaction times: A comment on Ruchalla et al. Intelligence 1986, 10, 93-100. [CrossRef]

60. Hale, S.; Jansen, J. Global processing-time coefficients characterize individual and group differences in cognitive speed. Psychol. Sci. 1994, 5, 384-389. [CrossRef]

61. Miller, J.; Ulrich, R. Mental chronometry and individual differences: Modeling reliabilities and correlations of reaction time means and effect sizes. Psychon. Bull. Rev. 2013, 20, 819-858. [CrossRef]

62. Blotenberg, I.; Schmidt-Atzert, L. On the characteristics of sustained attention test performance-The role of the preview benefit. 2019, submitted.

63. Rodriguez, M.C.; Maeda, Y. Meta-analysis of coefficient alpha. Psychol. Methods 2006, 11, 306-322. [CrossRef]

64. Taveira, A.D.; Choi, S.D. Review study of computer input devices and older users. Int. J. Hum. Comput. Interact. 2009, 25, 455-474. [CrossRef]

65. Düker, H. Leistungsfähigkeit und Keimdrüsenhormone; J.A. Barth: München, Germany, 1957.

66. Krumm, S.; Schmidt-Atzert, L.; Bracht, M.; Ochs, L. Coordination as a crucial component of performance on a sustained attention test. J. Individ. Differ. 2011, 32, 117-128. [CrossRef]

67. Deary, I.J.; Stough, C. Intelligence and inspection time. Am. Psychol. 1996, 51, 599-608. [CrossRef]

68. Vernon, P.A. Speed of Information-Processing and Intelligence; Ablex: Norwood, NJ, USA, 1987.

69. Grudnik, J.L.; Kranzler, J.H. Meta-analysis of the relationship between intelligence and inspection time. Intelligence 2001, 29, 523-535. [CrossRef]

70. Kranzler, J.H.; Jensen, A.R. The nature of psychometric g: Unitary process or a number of independent processes? Intelligence 1991, 15, 397-422. [CrossRef]

71. Muthén, L.K.; Muthén, B.O. Mplus User's Guide; Muthén \& Muthén: Los Angeles, CA, USA, 2015.

72. Townsend, J.T. Serial vs. parallel processing: Sometimes they look like tweedledum and tweedledee but they can (and should) be distinguished. Psychol. Sci. 1990, 1, 46-54. [CrossRef]

73. Schubert, A.-L.; Hagemann, D.; Voss, A.; Schankin, A.; Bergmann, K. Decomposing the relationship between mental speed and mental abilities. Intelligence 2015, 51, 28-46. [CrossRef]

74. Stafford, T.; Gurney, K.N. Additive factors do not imply discrete processing stages: A worked example using models of the Stroop task. Front. Psychol. 2011, 2. [CrossRef] [PubMed]

75. Neubauer, A.C.; Knorr, E. Elementary cognitive processes in choice reaction time tasks and their correlations with intelligence. Pers. Individ. Differ. 1997, 23, 715-728. [CrossRef]

(C) 2019 by the authors. Licensee MDPI, Basel, Switzerland. This article is an open access article distributed under the terms and conditions of the Creative Commons Attribution (CC BY) license (http://creativecommons.org/licenses/by/4.0/). 